\title{
Genetic Analysis in Anal and Cervical Cancer: Exploratory Findings About Radioresistance in the ProfiLER Database
}

\author{
ELISE ROWINSKI ${ }^{1}$, NICOLAS MAGNE ${ }^{2,3}$, WAFA BOULEFTOUR ${ }^{2}$, \\ PABLO MORENO-ACOSTA ${ }^{4}$, CHRISTELLE DE LA FOURCHADIERE ${ }^{5,6}$, \\ ISABELLE RAY-COQUARD ${ }^{5,6}$, QING WANG ${ }^{6}$, JEAN-YVES BLAY ${ }^{5,6}$ and OLIVIER TREDAN ${ }^{5,6}$ \\ ${ }^{1}$ Department of Medical Oncology, Lucien Neuwirth Cancer Institute, Saint-Priest-en-Jarez, France; \\ ${ }^{2}$ Department of Radiation Oncology, Lucien Neuwirth Cancer Institute, Saint-Priest-en-Jarez, France; \\ ${ }^{3}$ Laboratoire de Radiobiologie Cellulaire et Moléculaire, CNRS UMR 5822, \\ Institut de Physique Nucléaire de Lyon, IPNL, Lyon Medicine University, Lyon, France; \\ ${ }^{4}$ Research Group in Radiobiology Clinical, Molecular and Cellular, National Cancer Institute, Bogota, Colombia; \\ ${ }^{5}$ Department of Medical Oncology, Léon Bérard Cancer Centre, Lyon, France; \\ ${ }^{6}$ Department of Translational Research, Léon Bérard Cancer Centre, Lyon, France
}

\begin{abstract}
Background/Aim: This study aimed to describe genomic alterations on squamous cell cervical and anal carcinomas. Materials and Methods: From 2013 to 2019, 3,269 patients were included in the molecular screening ProfiLER trial. Only patients with non-metastatic cervical or anal cancer, and those initially treated with radiotherapy in a curative intent were selected. Genetic analyses were performed by next generation sequencing (NGS). Results: Genomic alterations were observed in most patients: 5 patients out of 15 (33.3\%) had at least one mutation on NGS and 4 out of 15 (26.7\%) had at least one aberration of the number of copies of genes in the comparative genomic hybridation (CGH) analysis. The most common mutated gene was PIK3CA. Conclusion: All omic approaches must be integrated in the locally advanced cancer setting by new clinical trial design to develop two routes in the treatment strategy: intensification or de-escalation treatment strategy according to omic markers.
\end{abstract}

To draw benefit from a cancer treatment, it is crucial that clinicians target patients with eligible tumor biomarkers. In

This article is freely accessible online.

Correspondence to: Dr. Esquis Wafa Bouleftour, Department of Medical Oncology, Institut de Cancérologie Lucien Newirth Saint Priest en Jarez, 108 Bis Avenue Albert Raimond 42270, Saint Priest en Jarez, France. Tel: +33 477917470, Fax: +33 477917497, e-mail: wafa.bouleftour@icloire.fr

Key Words: Genomic alterations, cervix carcinoma, anal carcinoma, omic markers, radioresistance. addition to traditional clinico-pathological factors, knowing about genomic alterations helps practitioners choose the best drug and/or radiation therapy, in short to decide on the right strategy. Indeed, it is now well established that cancers are frequently driven by specific genomic alterations (1). Thus, in the era of precision medicine, tumor genome analysis is a necessary prerequisite to better understand neoplasm pathology and outcome (2). The interest lies in both the diagnosis and therapeutic choices. The major challenge of such an approach is to improve patient outcomes by increasing efficacy and minimizing unnecessary side-effects.

In 2004, Samuels et al. reported a high frequency of mutations within coding regions of the phosphatidylinositol4,5-bisphosphate 3-kinase catalytic subunit alpha (PIK3CA) gene in tissues from a large variety of primary malignant tumors (3). PIK3CA mutation is a mechanism involved in hyper activation of PIK3/AKT pathway, well-known as a key regulator of cell-cycle proliferation, growth, survival, protein synthesis, and glucose metabolism. The PIK3CAAKT-mTor pathway was found to be over-expressed $(4,5)$. PIK3CA mutation was shown to predict better local response after irradiation for breast and head and neck cancers (6). The impact of PIK3CA mutation in cervix carcinomas is debated $(7,8)$ as, on the one hand, it has a positive impact on responsiveness (6) and on the other hand, it is a factor of radioresistance $(9,10)$. Gene profile assessments are rare in the literature about anal carcinomas. In a French large cohort between 1992 and 2015, 49 patients were screened and assessed with an omic approach (11). The most frequently altered pathway in the 49 tumors was the PI3K/Akt/Mtor pathway, it was altered in 22 out of the 49 tumors. 
The present study focused on squamous cell cervical and anal carcinomas included into the ProfiLER trial. The aim was to describe genomic alterations found in this subpopulation and determine if the same tendency of radiosensibility in PIK3CA-mutated squamous cell carcinoma can be found in these pelvic cancers.

\section{Materials and Methods}

From February 2013 to February 2019, 3,269 patients were included in the ProfiLER trial (NCT01774409) (12). ProfiLER programme is a large molecular screening program aiming to select molecularbased recommended therapies for metastatic cancer patients. Only patients with an initially non-metastatic squamous cell cervical or anal carcinoma were selected into the ProfiLER database for the present trial. Selected patients had to be initially treated with radiotherapy, in a curative intent for an early/or locally advanced disease. Patients with de novo initial metastatic diseases or without a complete genomic analysis were excluded from the accrual study. Patient and tumor characteristics, treatment data (radiotherapy and brachytherapy procedures, surgery, chemotherapy) and clinical outcomes were collected from medical records. The ProfiLER trial was conducted in accordance with the Good Clinical Practice Guidelines of the International Conference on Harmonization and the Declaration of Helsinki, and relevant European laws. All patients provided written consent. ProfiLER trial is registered with ClinicalTrials.Gov. Radioresistance is defined as a loco regional relapse (LRR) in the infield radiation after curative radiotherapy. The local-regional progression free survival (LRPFS) was defined as the time between the end of the curative therapeutic sequence including radiotherapy- and LRR. Response evaluation was performed clinically and pelvic MRI at 12 weeks after treatment completion. Patients without clinical and MRI (Magnetic resonance imaging) tumour were considered as complete responders.

Target genes were studied either on archival tumour sample $(n=9 / 15,60 \%)$ or on new biopsies of an accessible lesion $(n=6 / 15$, $40 \%$ ). Genetic analyses were performed by NGS (Next Generation Sequencing) to search mutations/insertions/deletions for 69 predefined cancer genes. The platform Ion Torrent PGM (Thermo Fisher Scientific, Waltham, MA, USA) was used for mutation screening. For each tumour sample, $10 \mathrm{ng}$ of DNA was used for the library construction using Ion AmpliSeqTM Library Kit 2.0 (Thermo Fisher Scientific) and then sequenced on an Ion 318TM Chip Kit V2 by Ion PGM system (Thermo Fisher Scientific) for 500 cycles according to the manufacturer's instruction. The raw signal data were analyzed using NextGENe Software Suite v3.4.2 (SoftGenetics, State College, PA, USA) and in-house bioinformatics pipeline. Microarray-based comparative genomic hybridization (CGH) was used to analyse copy number variations (CNV) of genes. So, $1.5 \mu \mathrm{g}$ of tumour DNA and $1.5 \mu \mathrm{g}$ of reference DNA (Promega \#G1471 or \#G1521, Madison, WI, USA) were at $95^{\circ} \mathrm{C}$ for 10 minutes to be denatured and fragmented. Tumour DNA was then chemically targeted with Kreatech's Universal Linkage System (ULSTM, Kreatech Diagnostics, Amsterdam, the Netherlands) Cy5dye, while reference DNA was targeted with Cy3-dye (Agilent \#5190-0450). Targeted samples were then purified and cohybridization was performed on $4 * 180 \mathrm{~K}$ Agilent SurePrint G3 Human whole-genome oligonucleotide arrays (Agilent \#G4449A), containing 180,000 oligonucleotide probes. Then, slides were washed, dried, scanned on the Agilent Surescan scanner and then processed and analysed. Amplifications and homozygous deletions were analyzed. Gains or simple deletions were excluded because they were not considered as clinically relevant. Then, genes were grouped according to main biological pathways using online databases as GenCards and PathCards in PIK3CA/AKT/mTOR, tyrosine kinase receptors, MAP kinases (Mitogen-activated protein kinases), apoptosis, angiogenesis, proliferation, and DNA damage control pathways. A more detailed description of sample processing, library preparation, predefined selected cancer genes, sequencing and raw data analysis has been published recently (13).

Statistical analyses were processed with R-3-2-2 (R Core Team $\mathrm{R}$ Foundation for Statistical Compting, Vienna, Austria). A descriptive analysis of population, tumour characteristics, treatment, and genomic alterations was first performed. LRFS and distant relapse survival (DRS) were extracted.

\section{Results}

Thirty patients with anal $(n=10)$ or cervix $(n=20)$ squamous cell carcinomas (SCC) out of 3,269 patients were included in the ProfiLER trial, corresponding to $0.9 \%$ of total patients. Fifteen patients were excluded from our study: 7 patients had an incomplete NGS or CGH analysis, 3 were not initially treated with radiotherapy and 5 had a de novo metastatic disease. Patient, treatment, outcome characteristics and NGS/CGS analysis are detailed in Table I. Fifteen patients were included in the present study: 6 out of $15(40 \%)$ had anal SCC and 9 out of $15(60 \%)$ had cervix SCC. Median age for the whole series was 42 years old (ranging from 31 to 64). The vast majority of patients were females (13 out of 15). Most tumors were staged as locally advanced disease (13 out 15$)$. All cervix carcinoma patients were initially treated with concomitant radio chemotherapy followed by brachytherapy +/- completion surgery. All anal carcinoma patients were treated with concomitant radio chemotherapy +/- brachytherapy with no completion surgery procedure.

Regarding genomic alterations, 5 patients out of 15 (33.3\%) had at least one mutation on NGS and 4 out of 15 (26.7\%) had at least one aberration of the number of copies of genes in $\mathrm{CGH}$ analysis. The most common mutated gene was PIK3CA. Three patients out of 15 (20\%) had a PIK3CA mutation: 1 had anal SCC and 2 had cervical SCC. We observed 1 cervical SCC out of 9 had TSC1 mutation (11.1\%), 1 had ROS1 mutation and 1 had MPL mutation. As to anal SCC, 1 patient out of 6 had a DDB2 mutation (16.7\%).

Nine patients out of $15(60 \%)$ had a local relapse in the radiation field corresponding to our definition of radio resistance tumor. Median follow-up was 5 years (range $=1$ 12 years) for the 15 cases. Median time to LRRS was 12 months (range=6-46) and 5 months (range=3-46) in cervix and anal carcinomas, respectively. Median time to DRS was 45 months (range 1 to 54) and 22 months (range=3-60) in cervix and anal carcinomas, respectively. Median follow-up was 7 years (range $=1-12$ years). At last follow-up, 3 patients 


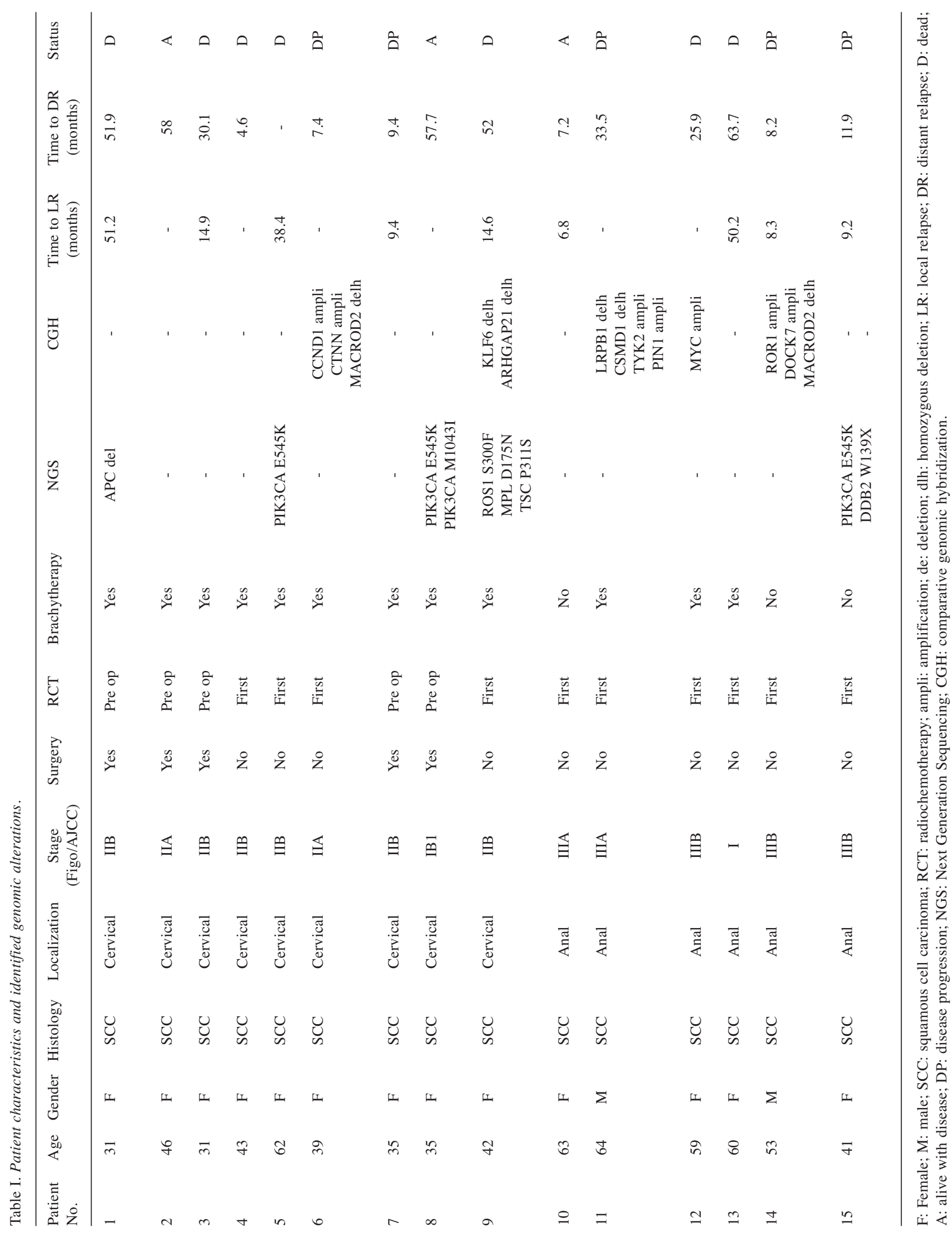


were still alive, 12 had deceased due to cancer. Median overall survival was 54 and 31 months in cervix and anal carcinomas, respectively.

\section{Discussion}

In the present small case series, we observed that $22.3 \%$ of cervical SCC had a PIK3CA mutation. These data are consistent with the date collected in literature. Indeed, there is a wide range of PIK3CA mutations in cervical SCC: $5 \%$ to $37.5 \%(13-15)$ and $14 \%$ in COSMIC (Catalogue of Somatic Mutations in Cancer) database (16). In cervical cancer, activating mutations in the PIK3CA gene have been found almost exclusively in exon 9 (14). The two PIK3CA mutations identified in our study were located in the exon 9 helical domain (E545K), a well-described hotspot mutation that resulted in constitutive activation of cellular signaling (17). The fact that a small number of patients were included did not enable us to perform a statistical analysis of survival or local relapse after chemo-radiotherapy. Several trials suggested that PIK3CA mutations were associated with shorter survival [67.1 vs. 90.3 months ( $\mathrm{HR}=9.1,95 \%$ $\mathrm{CI}=2.8-29.5, p<0.001)]$ for Wright et al. (15). McIntyre et al. (2013) also reported that in patients treated with radical chemo-radiotherapy for a cervix cancer, the PIK3CA mutation status was strongly associated with overall survival in FIGO stage IB/II but not stage III/IVA (10). De la Rochefordiere et al. came to the same conclusion with a poor response and a poor survival after definitive radiotherapy for cervical SCC with PIK3CA mutations (18). Conversely, Libing Xiang et al. reported a better treatment outcome for patients with PIK3CA mutations (HR $=0.54,95 \%$ CI $=0.29$ $0.99, p=0.048$ ) and PIK3CA mutations were significantly associated with less distant metastases (7). The same trend was observed in a study performed by Hou et al. The presence of PIK3CA mutations was associated with a significantly longer overall survival (median: 9.4 months) unlike the absence of PIK3CA mutations (median, 4.2 months; $p=0.019$ ) (19). The size of cohorts, heterogeneity of samples and heterogeneity of administrated treatment (surgery, chemotherapy and chemo-radiotherapy) might explain those contradictory outcomes. More recently, a systematic review supported a potential negative effect of PIK3CA mutation in cervical SCC (20). Regarding anal SCC, only two patients had a genomic mutation. One patient had a PIK3CA mutation on exon 9 (E545K). PIK3CA mutation is the most frequent mutated gene in anal SCC (2123). To our knowledge, very few studies focused on PIK3CA mutation and outcome in anal SCC. Cacheux et al. evaluated PIK3CA mutation and outcomes in patients with anal SCC. PIK3CA mutation was associated with poor outcome for patients treated with abdominoperineal resection after local relapse post- chemo-radiotherapy (24).
Interestingly and reported twice by our team, PIK3CA mutations were found to be prognostic factors of locoregional relapse in breast and head and neck cancers. This alteration was associated with favorable local-regional progression free survival (6).

This prospective study highlights the occurrence of PIK3CA mutation in pelvic squamous cell carcinoma. However certain limitations must be taken into account. Firstly, in view of our small sample, we could not reasonably perform statistical analysis of patient outcome and genomic alterations. Moreover, subgroup analysis was also not performed. It seems important to achieve data collection from a larger cohort to determine if PIK3CA mutation is correlated with pelvic SCC outcome. Thus, results of this study must be interpreted with caution due to the small number of patients included. Furthermore, molecular screening was carried out in $60 \%$ of cases on archived tumors and in $40 \%$ of cases on new biopsies of an accessible lesion. This heterogeneity does not allow to analyze the influence of antineoplastic treatments on the molecular results.

Despite the emergence of an increasing number of innovative drugs, the notion of treatment de-escalation in medicine is still being explored for infectious disease management (25). A de-escalation concept is also typically interesting for cancer treatment particularly in adjuvant strategies. In such case, this concept implies a reduction of toxicity burden, while maintaining the highest efficacy.

Ultimately, it could be useful to know if PIK3CA mutation could be regarded as a biomarker. This could enable practitioners to consider de-escalation strategies in PIK3CA-mutated SCC as in breast or head and neck cancer patients, for whom clinical trials are being designed. To conclude, all omic approaches must be integrated in the locally advanced cancer setting by a new clinical trial design in order to develop two routes of treatment strategy: intensification or de-escalation treatment, according to omic markers.

\section{Conflicts of Interest}

The Authors declare no conflicts of interest.

\section{Authors' Contributions}

E.R performed the analysis and wrote the article. W.B and N.M reviewed the analysis and provided feedback. P.M, C.D, I.R, Q.W, J.B, O.T supervised the study design. All Authors read and approved the final version of the article.

\section{Acknowledgements}

The Authors wish to thank Sandrine Sotton for her assistance with the English version of this article. 


\section{References}

1 Hanahan D and Weinberg RA: Hallmarks of cancer: the next generation. Cell 144(5): 646-674, 2011. PMID: 21376230. DOI: 10.1016/j.cell.2011.02.013

2 Mery B, Vallard A, Rowinski E and Magne N: High-throughput sequencing in clinical oncology: from past to present. Swiss Med Wkly 149: w20057, 2019. PMID: 30946479. DOI: 10.4414/smw.2019.20057

3 Samuels Y, Wang Z, Bardelli A, Silliman N, Ptak J, Szabo S, Yan H, Gazdar A, Powell SM, Riggins GJ, Willson JK, Markowitz S, Kinzler KW, Vogelstein B and Velculescu VE: High frequency of mutations of the PIK3CA gene in human cancers. Science 304(5670): 554, 2004. PMID: 15016963. DOI: 10.1126/science.1096502

4 Hennessy BT, Smith DL, Ram PT, Lu Y and Mills GB: Exploiting the PI3K/AKT pathway for cancer drug discovery. Nat Rev Drug Discov 4(12): 988-1004, 2005. PMID: 16341064. DOI: $10.1038 / \operatorname{nrd} 1902$

5 Garcia-Echeverria C and Sellers WR: Drug discovery approaches targeting the PI3K/Akt pathway in cancer. Oncogene 27(41): 5511-5526, 2008. PMID: 18794885. DOI: 10.1038/onc.2008.246

6 Bernichon E, Vallard A, Wang Q, Attignon V, Pissaloux D, Bachelot T, Heudel PE, Ray-Coquard I, Bonnet E, de la Fouchardière A, Faure C, Chopin N, Beurrier F, Racadot S, Sunyach MP, Rancoule C, Perol D, Corset V, Agrapart V, Tinquaut F, Blay JY, Magné $\mathrm{N}$ and Trédan O: Genomic alterations and radioresistance in breast cancer: an analysis of the ProfiLER protocol. Ann Oncol 28(11): 2773-2779, 2017. PMID: 28945826. DOI: 10.1093/annonc/mdx488

7 Xiang L, Jiang W, Li J, Shen X, Yang W, Yang G, Wu X and Yang H: PIK3CA mutation analysis in Chinese patients with surgically resected cervical cancer. Sci Rep 5: 14035, 2015. PMID: 26358014. DOI: 10.1038/srep14035

8 Akbarov K, Isayev I, Melikova L, Quliyev E and Aliyeva N: EP1507: Tumor response rate depending on PIK3CA mutation status in Azerbaijanian cervical cancer patients. Radiotherapy and Oncology 127: S817, 2018. DOI: 10.1016/S0167-8140 (18) $31816-4$

9 Arjumand W, Merry CD, Wang C, Saba E, McIntyre JB, Fang S, Kornaga E, Ghatage P, Doll CM and Lees-Miller SP: Phosphatidyl inositol-3 kinase (PIK3CA) E545K mutation confers cisplatin resistance and a migratory phenotype in cervical cancer cells. Oncotarget 7(50): 82424-82439, 2016 PMID: 27489350. DOI: 10.18632/oncotarget.10955

10 McIntyre JB, Wu JS, Craighead PS, Phan T, Köbel M, Lees-Miller SP, Ghatage P, Magliocco AM and Doll CM: PIK3CA mutational status and overall survival in patients with cervical cancer treated with radical chemoradiotherapy. Gynecol Oncol 128(3): 409-414, 2013. PMID: 23266353. DOI: 10.1016/j.ygyno.2012.12.019

11 Cacheux W, Tsantoulis P, Briaux A, Vacher S, Mariani P, Richard-Molard M, Buecher B, Richon S, Jeannot E, Lazartigues J, Rouleau E, Mariani O, El Alam E, Cros J, Roman-Roman S, Mitry E, Girard E, Dangles-Marie V, Lièvre A and Bièche I: Array comparative genomic hybridization identifies high level of $\mathrm{PI} 3 \mathrm{~K} / \mathrm{Akt} / \mathrm{mTOR}$ pathway alterations in anal cancer recurrences. Cancer Med 7(7): 3213-3225, 2018. PMID: 29804324. DOI: $10.1002 /$ cam4.1533

12 Trédan $\mathrm{O}$, Wang Q, Pissaloux D, Cassier $\mathrm{P}$, de la Fouchardière A, Fayette J, Desseigne F, Ray-Coquard I, de la Fouchardière C,
Frappaz D, Heudel PE, Bonneville-Levard A, Fléchon A, Sarabi M, Guibert P, Bachelot T, Pérol M, You B, Bonnin N, Collard O, Leyronnas C, Attignon V, Baudet C, Sohier E, Villemin JP, Viari A, Boyault S, Lantuejoul S, Paindavoine S, Treillleux I, Rodriguez C, Agrapart V, Corset V, Garin G, Chabaud S, Pérol D, Blay JY and ProfiLER investigators: Molecular screening program to select molecular-based recommended therapies for metastatic cancer patients: analysis from the ProfiLER trial. Ann Oncol 30(5): 757-765, 2019. PMID: 30865223. DOI: 10.1093/ annonc/mdz080

13 Tornesello ML, Annunziata C, Buonaguro L, Losito S, Greggi S and Buonaguro FM: TP53 and PIK3CA gene mutations in adenocarcinoma, squamous cell carcinoma and high-grade intraepithelial neoplasia of the cervix. J Transl Med 12: 255, 2014. PMID: 25220666. DOI: 10.1186/s12967-014-0255-5

14 Ojesina AI, Lichtenstein L, Freeman SS, Pedamallu CS, ImazRosshandler I, Pugh TJ, Cherniack AD, Ambrogio L, Cibulskis K, Bertelsen B, Romero-Cordoba S, Treviño V, Vazquez-Santillan K, Guadarrama AS, Wright AA, Rosenberg MW, Duke F, Kaplan B, Wang R, Nickerson E, Walline HM, Lawrence MS, Stewart C, Carter SL, McKenna A, Rodriguez-Sanchez IP, Espinosa-Castilla M, Woie K, Bjorge L, Wik E, Halle MK, Hoivik EA, Krakstad C, Gabiño NB, Gómez-Macías GS, Valdez-Chapa LD, GarzaRodríguez ML, Maytorena G, Vazquez J, Rodea C, Cravioto A, Cortes ML, Greulich H, Crum CP, Neuberg DS, Hidalgo-Miranda A, Escareno CR, Akslen LA, Carey TE, Vintermyr OK, Gabriel SB, Barrera-Saldaña HA, Melendez-Zajgla J, Getz G, Salvesen $\mathrm{HB}$ and Meyerson M: Landscape of genomic alterations in cervical carcinomas. Nature 506(7488): 371-375, 2014. PMID: 24390348. DOI: 10.1038/nature12881

15 Wright AA, Howitt BE, Myers AP, Dahlberg SE, Palescandolo E, Van Hummelen P, MacConaill LE, Shoni M, Wagle N, Jones RT, Quick CM, Laury A, Katz IT, Hahn WC, Matulonis UA and Hirsch MS: Oncogenic mutations in cervical cancer: genomic differences between adenocarcinomas and squamous cell carcinomas of the cervix. Cancer 119(21): 3776-3783, 2013. PMID: 24037752. DOI: 10.1002/cncr.28288

16 Forbes SA, Bhamra G, Bamford S, Dawson E, Kok C, Clements J, Menzies A, Teague JW, Futreal PA and Stratton MR: The Catalogue of Somatic Mutations in Cancer (COSMIC). Curr Protoc Hum Genet Chapter 10: Unit 10.11, 2008. PMID: 18428421. DOI: 10.1002/0471142905.hg1011s57

17 Courtney KD, Corcoran RB and Engelman JA: The PI3K pathway as drug target in human cancer. J Clin Oncol 28(6): 1075-1083, 2010. PMID: 20085938. DOI: 10.1200/JCO.2009.25.3641

18 de la Rochefordiere A, Kamal M, Floquet A, Thomas L, Petrow P, Petit T, Pop M, Fabbro M, Kerr C, Joly F, Sevin E, Maillard S, Curé H, Weber B, Brunaud C, Minsat M, Gonzague L, Berton-Rigaud D, Aumont M, Gladieff L, Peignaux K, Bernard V, Leroy Q, Bieche I, Margogne A, Nadan A, Fourchotte V, Diallo A, Asselain B, Plancher C, Armanet S, Beuzeboc P and Scholl SM: PIK3CA pathway mutations predictive of poor response following standard radiochemotherapy \pm cetuximab in cervical cancer patients. Clin Cancer Res 21(11): 2530-2537, 2015. PMID: 25724520. DOI: 10.1158/1078-0432.CCR-14-2368

19 Hou MM, Liu X, Wheler J, Naing A, Hong D, Coleman RL, Tsimberidou A, Janku F, Zinner R, Lu K, Kurzrock R and Fu S: Targeted PI3K/AKT/mTOR therapy for metastatic carcinomas of the cervix: A phase I clinical experience. Oncotarget 5(22): 1116811179, 2014. PMID: 25426553. DOI: 10.18632/oncotarget.2584 
20 Pergialiotis V, Nikolaou C, Haidopoulos D, Frountzas M, Thomakos N, Bellos I, Papapanagiotou A and Rodolakis A: PIK3CA mutations and their impact on survival outcomes of patients with cervical cancer: a systematic review. Acta Cytol 64(6): 547-555, 2020. PMID: 32683364. DOI: 10.1159/000509095

21 Cacheux W, Dangles-Marie V, Rouleau E, Lazartigues J, Girard E, Briaux A, Mariani P, Richon S, Vacher S, Buecher B, Richard-Molard M, Jeannot E, Servant N, Farkhondeh F, Mariani O, Rio-Frio T, Roman-Roman S, Mitry E, Bieche I and Lièvre A: Exome sequencing reveals aberrant signalling pathways as hallmark of treatment-naive anal squamous cell carcinoma. Oncotarget 9(1): 464-476, 2017. PMID: 29416628. DOI: $10.18632 /$ oncotarget.23066

22 Chung JH, Sanford E, Johnson A, Klempner SJ, Schrock AB, Palma NA, Erlich RL, Frampton GM, Chalmers ZR, Vergilio J, Rubinson DA, Sun JX, Chmielecki J, Yelensky R, Suh JH, Lipson D, George TJ Jr, Elvin JA, Stephens PJ, Miller VA, Ross JS and Ali SM: Comprehensive genomic profiling of anal squamous cell carcinoma reveals distinct genomically defined classes. Ann Oncol 27(7): 1336-1341, 2016. PMID: 27052656. DOI: $10.1093 /$ annonc/mdw152
23 Bernardi MP, Ngan SY, Michael M, Lynch AC, Heriot AG, Ramsay RG and Phillips WA: Molecular biology of anal squamous cell carcinoma: implications for future research and clinical intervention. Lancet Oncol 16(16): e611-e621, 2015. PMID: 26678214. DOI: 10.1016/S1470-2045(15)00292-2

24 Cacheux W, Rouleau E, Briaux A, Tsantoulis P, Mariani P, Richard-Molard M, Buecher B, Dangles-Marie V, Richon S, Lazartigues J, Jeannot E, Farkhondeh F, Sastre-Garau X, de La Rochefordière A, Labib A, Falcou MC, Stevens D, Roth A, Roman-Roman S, Mitry E, Bièche I and Lièvre A: Mutational analysis of anal cancers demonstrates frequent PIK3CA mutations associated with poor outcome after salvage abdominoperineal resection. Br J Cancer 114(12): 1387-1394, 2016. PMID: 27219019. DOI: $10.1038 / b j c .2016 .144$

25 Masterton RG: Antibiotic de-escalation. Crit Care Clin 27(1): 149-162, 2011. PMID: 21144991. DOI: 10.1016/j.ccc.2010. 09.009

Received March 25, 2021

Revised April 19, 2021

Accepted April 20, 2021 